\section{G. Burdea}

CAIP Center, Rutgers University

Piscataway, New Jersey, USA

\section{Review Paper}

\section{Virtual Rehabilitation - Benefits and Challenges ${ }^{1}$}

\begin{abstract}
Virtual rehabilitation represents the provision of therapeutic interventions locally or at a distance, using Virtual Reality hardware and simulations. Such therapy has been applied to various patient populations, including musculo-skeletal, post-stroke, and cognitively-impaired. This article reviews the benefits brought by VR-enhanced and VR-based rehabilitation to the above patient groups. Also discussed are the many challenges in integrating this new technology into the medical care system.
\end{abstract}

\section{Introduction}

Virtual Reality technology has been commercially available since the late 80 's, with the first systems sold by VPL Research. A dramatic improvement in computer technology, coupled with better programming tools have contributed to the "rebirth" of VR in the late 90's. Currently its application domains (with significant cost advantage) range from the oil and gas industry, to manufacturing (especially airplanes and cars), to military and medical care.

Within Medicine, VR has been used in teaching anatomy, training in diagnostic procedures (such as virtual colonoscopy, or virtual bronchroscopy), teaching open and minimally-invasive surgery procedures, and in rehabilitation. Within the scope of this article, we are interested in Virtual Rehabilitation, which can be defined as the provision of therapy using VR hardware and simulations. While newer than other medical VR application domains, it is growing at an incredible pace in the US, Europe and Asia. A testimonial to the ongoing research into what may soon revolutionize the "art" of therapy are several recent conferences focusing on Virtual Rehabilitation.

The present review of Virtual Rehabilitation starts with ways to classify it. Subsequently its many benefits are discussed, looking at therapeutic approaches, medical efficacy and patient's subjective reaction to the technology. Our enthusiasm for this new field of Medicine is tempered by the realization that many challenges exist, from equipment issues, to cost and the attitude of the therapist community towards this new technology. The article ends with a summary of benefits/challenges, some being common to all forms of Virtual Rehabilitation, some being specific to a given patient population. This review is by no means all-encompassing, owing to space and time limitations. Many projects exist, in various stages of development, from concept to prototype, toclinical pilot studies, in addition to those mentioned here.

\section{Types of Virtual Rehabilitation}

There are several ways to classify Virtual Rehabilitation. An obvious one is related to the specific patient population it is destined for. Thus we can distinguishmusculo-skeletal Virtual Rehabilitation, post-stroke Virtual Rehabilitation, and cognitive Virtual Rehabilitation, among others. Musculoskeletal (orthopedic) patients are those that suffered a bone or muscle/ligament injury, are younger and more numerous than other patients needing rehabilitation. For example, in the United States, every day 25,000 individuals sprain

\footnotetext{
${ }^{1}$ Based on the Key note address with the same title given at the $1^{\text {st }}$ International Workshop on Virtual Rehabilitation, Lausanne, Switzerland, November 7-8, 2002. (C) Grigore Burdea
} 
their ankle, according to the American Association of Orthopedic Surgeons [1]. Post-stroke patients are those that have survived a neural hemorrhage, or blood clot to the brain, resulting in paralysis to half of their body. There are 500,000 such new cases yearly, according to the American Stroke Association [2]. The cognitive patient population groups individuals with various psychological disorders, ranging from attention deficit/ hyperactivity, to eating disorders, to post-traumatic stress and phobias [10].

Another way to classify Virtual Rehabilitation relates to the rehabilitation protocol. Here we distinguish VR-augmented and VRbased therapy. In VR-augmented rehabilitation patients receive a mixture of "classical" exercises, done on equipment available in the clinic (or at home), as well as a VR regimen of simulation exercises. Rehabilitation which is VR-based eliminates the classical exercises entirely, and is a newer approach compared to VRaugmented therapy.

Virtual Rehabilitation simulations differ depending on the particular therapeutic approach, such as "teaching by example," "video gamelike," and "exposure therapy." Teaching by example has been used to treat post-stroke chronic patients by researchers at the Massachusetts Institute of Technology. As shown in Figure 1a [8], motor training of the arm reach motion is done with a "teacher" object (in this case a cube). The required motion trajectory, typical of a frontal reach task, is visualized to help the patients. Their arm motion is tracked and mapped to the motion of another virtual object following the teacher's example. By contrast, Figure 1b [3] shows a video game-like approach, where the patient pilots an airplane through 3-D hoops. Here there is no teacher object, and the patient has a higher cognitive load when performing the exercise.

a)

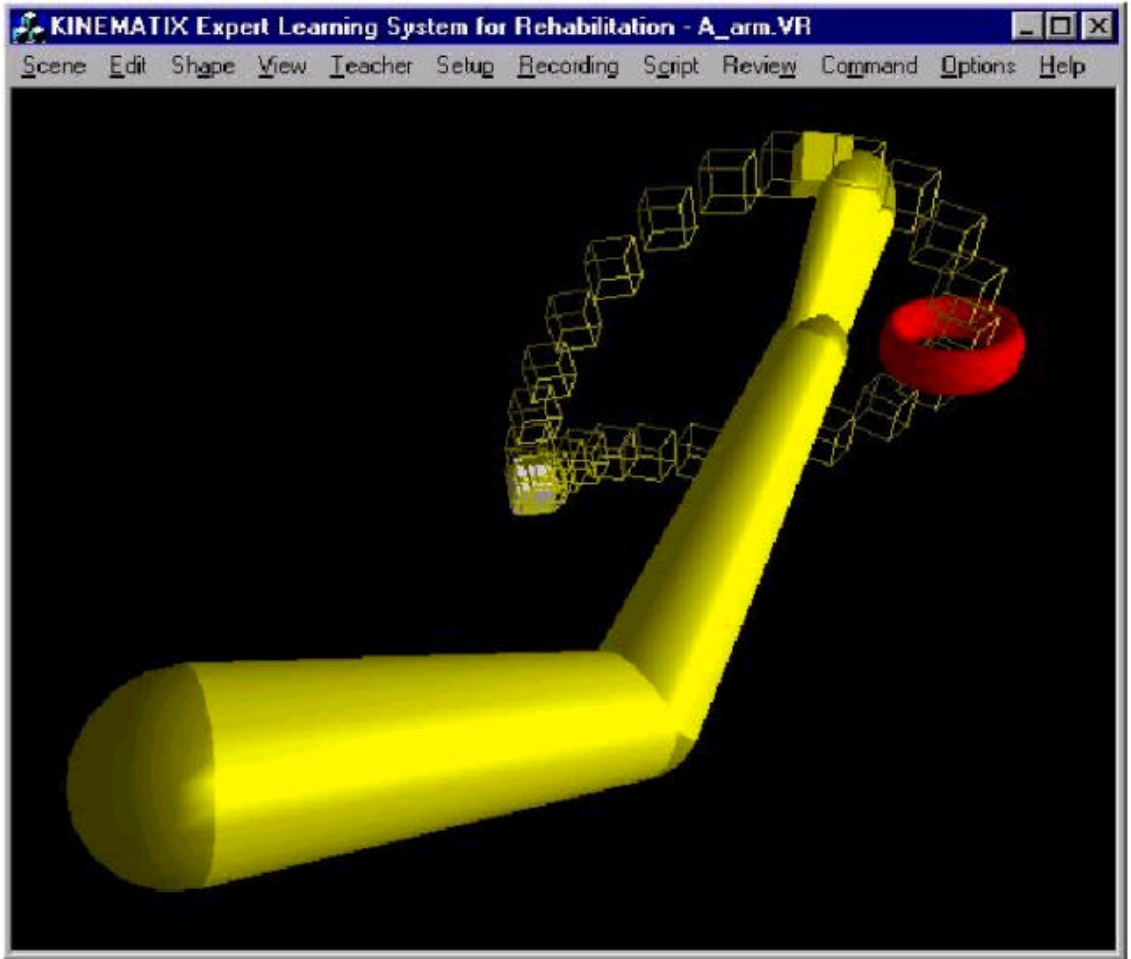

b)

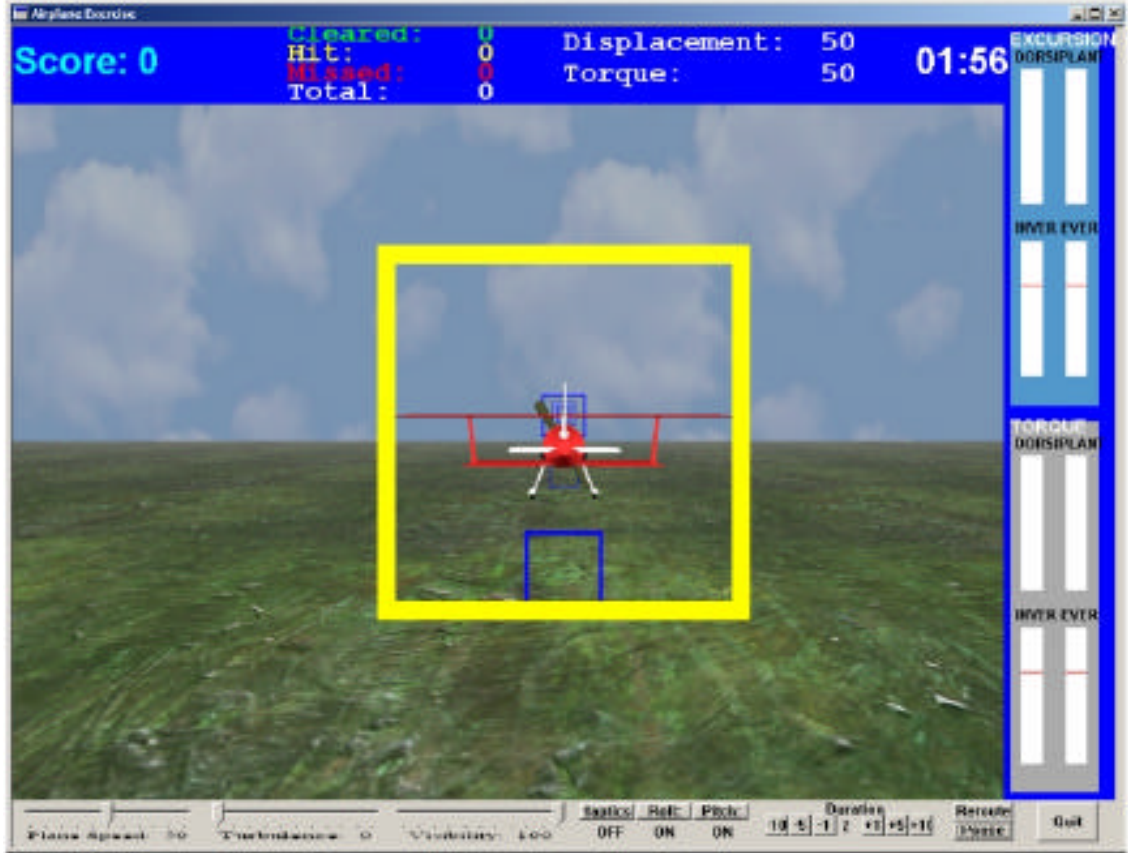

Fig. 1. Various Virtual Rehabilitation therapeutic approaches: a) teaching by example [8] ( Lawrence Erlbaum 2002. Reprinted by permission; b) video-game exercise simulation. () Rutgers University 2002. Reprinted by permission.

Finally, onecan classify Virtual Rehabilitation according to the proximity to the therapist (or therapeutic team) assisting the patient. If the therapists are nearby, the therapy is local, such as in an outpatient clinic environment.
However, if the therapist is remote, then therapy is administered through a Virtual Telerehabilitation approach. Telerehabilitation is a newer form of virtual rehabilitation than clinic-based therapy, and is less developed at this time. 


\section{Benefits of Virtual Rehabilitation}

Before discussing the benefits of Virtual Rehabilitation, let us first look at some of the characteristics of classical rehabilitation. One adjective comes to mind... "boring." Indeed, rehabilitation is by its nature repetitive, and repetition tends to "decouple" the mind, and reduce patient's motivation. Another characteristic is the predominance of simple mechanical devices with little or no computerized sensing. Thus there are no widespread online databases, and there are errors in interpreting evaluation data. Such errors are both positional and temporal, since the temporal granularity of manual data recording is low. Traditional rehabilitation is done one-to-one, meaning that one therapist (or sometimes several) is working with one patient. Thus costs are high, especially for demanding patients such as those with traumatic brain injury or spinal chord injury. For the portion of therapy that the patient is doing at home, there currently is no monitoring. This results in varying degrees of compliance with the prescribed exercise regimen, and a larger than necessary variability in treatment outcome. Finally, the distribution of therapists over the territory is uneven. They tend to gravitate towards urban areas, and away from rural or remote locations, where their practice is more difficult. More than 50 million Americans live in rural areas, however, only $10 \%$ of therapists practice there, according to a recent National Rural Health Association survey [9]. This situation forces patients to travel to mostly-urban clinics, with the resulting additional expenses and disruption in family life.

The advantages associated with the use of Virtual Rehabilitation are numerous. The same VR hardware can be used for various types of patients, as well as for various types of exercises done on those patients. For example, the same head-mounted display can be used for patients suffering from "Vietnam syndrome" (a form of posttraumatic stress disorder), as well as for children with attention deficits, or for post-stroke patients. Similarly, the same sensing glove can be used to train musculo-skeletal patients to squeeze "rubber balls," or to do a pegboard exercise. The rubber ball squeezing is a typical strengthening exercised prescribed after hand surgery, and corresponds with rehabilitation at the impairment level. The peg-board exercise, such as the one shown in Figure 2 [11], is a procedure done to improve hand-eye coordination (and possibly upper arm extension). It represents rehabilitation done at the (higher) functional level. Of course, there are no real peg-boards, or rubber balls, or any other equipment, except for the haptic glove. Thus a major advantage in all forms of Virtual Rehabilitation is economy of scale.

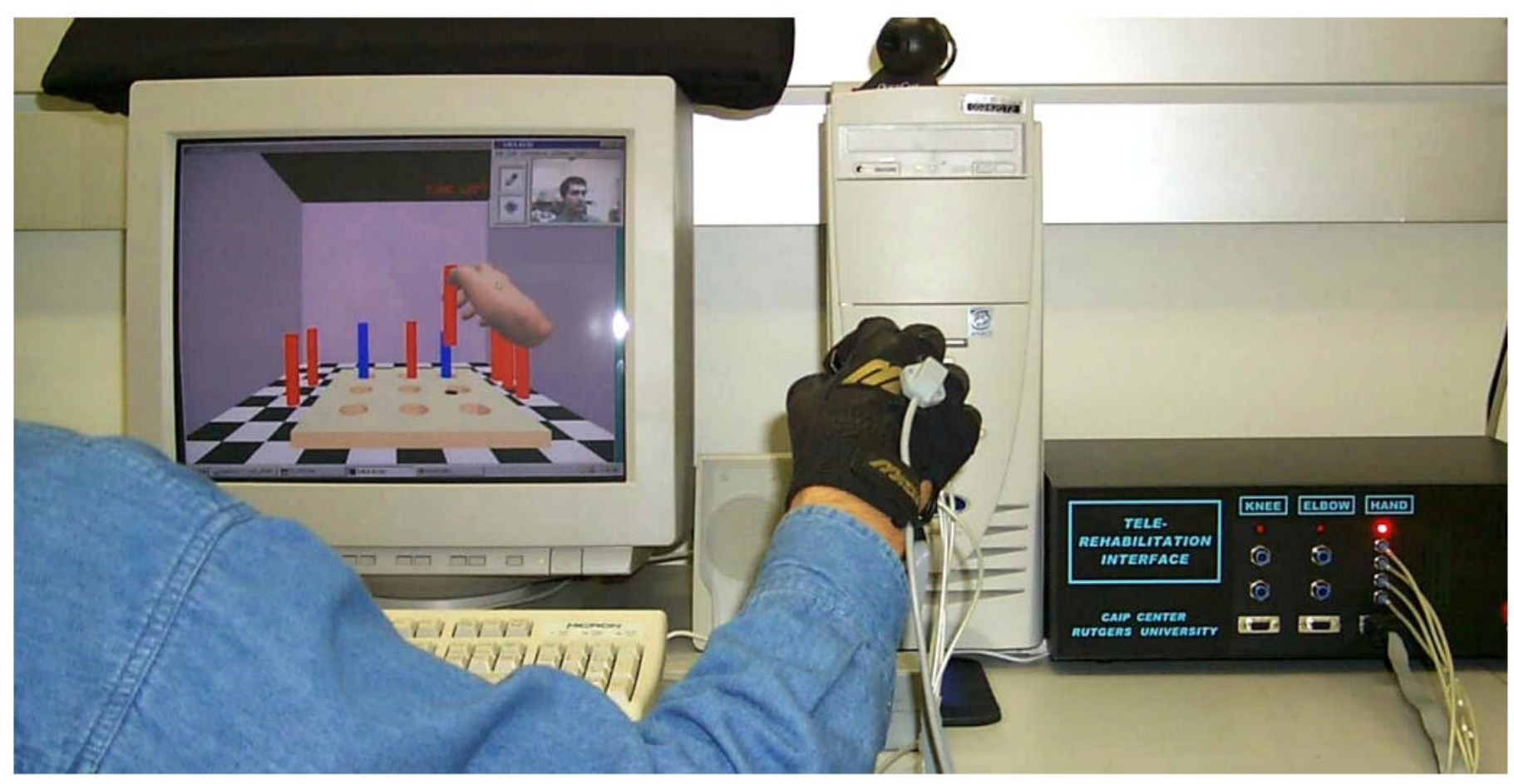

Fig. 2. The VR-based orthopedic rehabilitation using a haptic glove during a peg-board exercise. () IEEE 2000. Reprinted by permission. 
Another advantage present in all forms of Virtual Rehabilitation is interactivity and patient motivation. This is especially true in video game-based therapeutic approaches, where the patient competes against the computer. By providing visual and auditory rewards, such as displaying gratifying messages in real time ("Great", "Very Good," etc.), patients are motivated to exercise. It has been even suggested that in the future patients may compete againsteach otherin such rehabilitation games [5]. In other words they will get better while having fun!

Virtual Rehabilitation systems rely on computers to render and display the exercises, and on sensorized interfaces to mediate the patient's actions. As such data flows naturally to the host computer, at a frequency and resolution that are unmatched by traditional mechanical evaluation tools. The high temporal granularity of data, such as joint motion, or finger force output, is also important. One potential use of this intrinsic capability of Virtual Rehabilitation is to discern whetherthe patient is "malingering." This medical term describes patients that purposely do not exercise at their full capacity, for reasons of medical benefits, worker's compensation and such.

Thus patient data gathered during Virtual Rehabilitation is transparently stored in online databases, without the patient's or therapist's action. Access to this data can be done either through phone lines, or through the Internet. When the Internet is used, data can be uploaded through clientserver communication, or through web access. If data is made available over the web, it needs to be passwordprotected, in order to preserve the patient's confidentiality. Once in a database, clinical measures can be viewed remotely, as shown in Figure 3. This represents the increase in a poststroke patient's endurance during hand strengthening exercises over three weeks of VR-based therapy (August 13 to 30,2001 ). The small bar graph to the left represents the baseline (the patient's initial capability before therapy). The data was sampled in Newark (New Jersey, USA), and accessed over the web, from the author's location 50 kilometers away.

Remote data access is one fundamental requirement of Telerehabilitation, where patients are remote from clinics and therapists. This represents a great benefit for rural patients, since they do not have to travel to urban clinics. Rural area therapy at home relies heavily on therapist assistants, who have less skill and experience than regular therapists. In that case Tele-consultation may provide expertise from specialists at tertiary care facilities, such as university hospitals, and thus improve quality of care and outcomes. Telerehabilitation is beneficial in reducing healthcare costs as well. For example, Buckley and colleagues at the Catholic University of America [4] report on a study of nursing management for stroke patients and their caregivers (usually spouses). They found that Tele-consultation visits averaged 20-25 minutes, compared to home care visits that took 30-60 minutes (plus another 60 minutes in travel time). Thus the cost of a nurse visit was reduced by more than half (from $\$ 75$ to $\$ 30$ for a Tele-consultation visit).

Anotherpossible way in which costs will be reduced in the future is through multiplexed Telerehabilitation. This arrangement takes advantage of the intelligence available in the home PC, which can supplant the therapist some of the time. In this case a therapist will be able to monitor several patients exercising simultaneously at home, a departure from the one-to-one paradigm prevalent today. Telerehabilitation has also been found toimprove compliance by musculo-skeletal patients exercising at home, as was recently reported in a study conducted by Eastman Kodak Company and Greenleaf Medical Systems [5].

The Virtual Rehabilitation advantages listed above are applicable across patient populations. There are however advantages which are specific to a

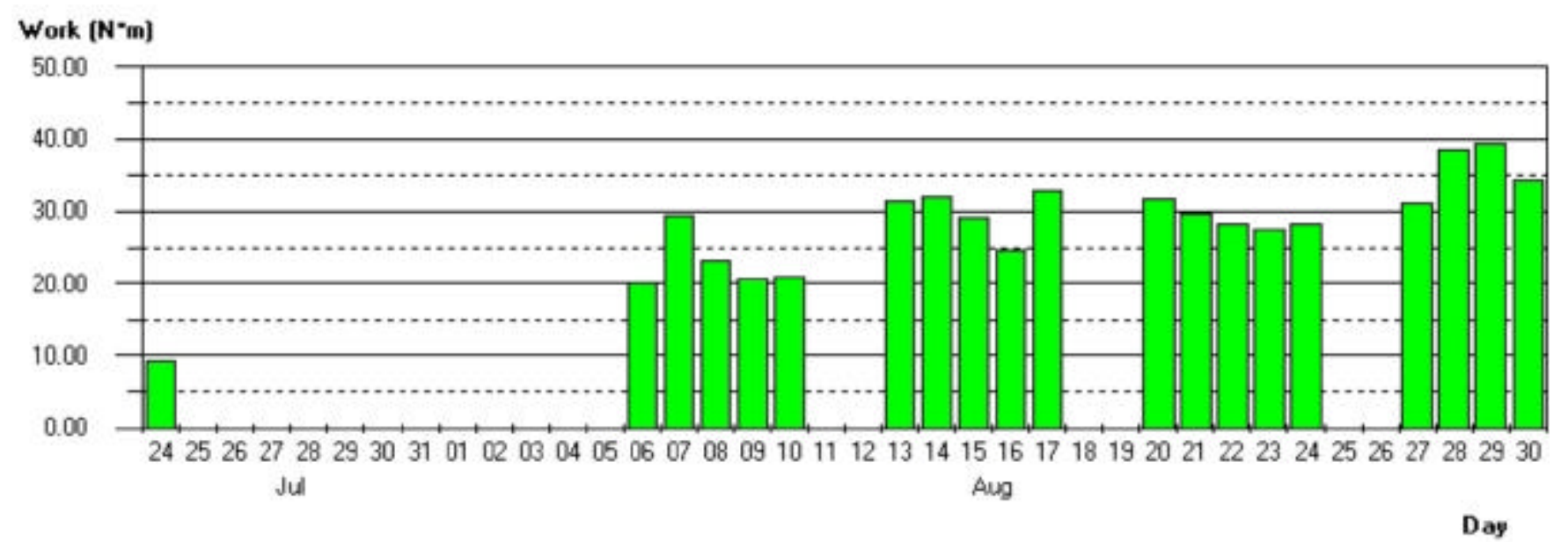

Fig. 3. Remote access of hand strengthening data obtained during VR-based rehabilitation of a post-stroke patient. @ Rutgers University 2002. Reprinted by permission. 
certain type of Virtual Rehabilitation. Patients with fear of flying, for example, are asked to take real flights with a therapist, as a way to desensitize them. Clearly, their privacy suffers, as sweating, tremor, and other manifestations of their illness are witnessed by passengers and crew. By contrast, Virtual Rehabilitation can be done in a therapist's office in complete privacy, as illustrated in Figure 4a [7]. Studies conducted at Georgia Institute of Technology and Emory Health Sciences [6] report that VR therapy was as efficacious as classical fear of flying therapy. A year after VR exposure $92 \%$ of patients maintained their gains and had flown on airplanes. Furthermore, the cost of therapy was reduced (cost of airline tickets, and therapist time).

Virtual Rehabilitation is particularly useful for those with post-traumatic stress syndrome, as found in Vietnam veterans. Again their privacy is maintained, as they are exposed to helicopter flights over hostile territory (see Figure 4b [7]). Taking patients to Vietnam is a more expensive and sometimes impractical solution. Exposure therapy in VR is also safer, as in the case of patients experiencing fear of spiders, or snakes. They can view these creatures in VR, without ever being poisoned.

\section{Challenges posed by Virtual Rehabilitation}

For all its benefits, Virtual Rehabilitation does pose significant challenges for its widespread adoption. The first is clinical acceptance, which is conditioned on proven medical efficacy and on a proactive therapist response. Medical studies are underway, and not enough data exist to satisfy critics that VR-augmented, or VR-based rehabilitation, is viable. In all fairness it should be said that initial data from pilot studies is indeed

a)

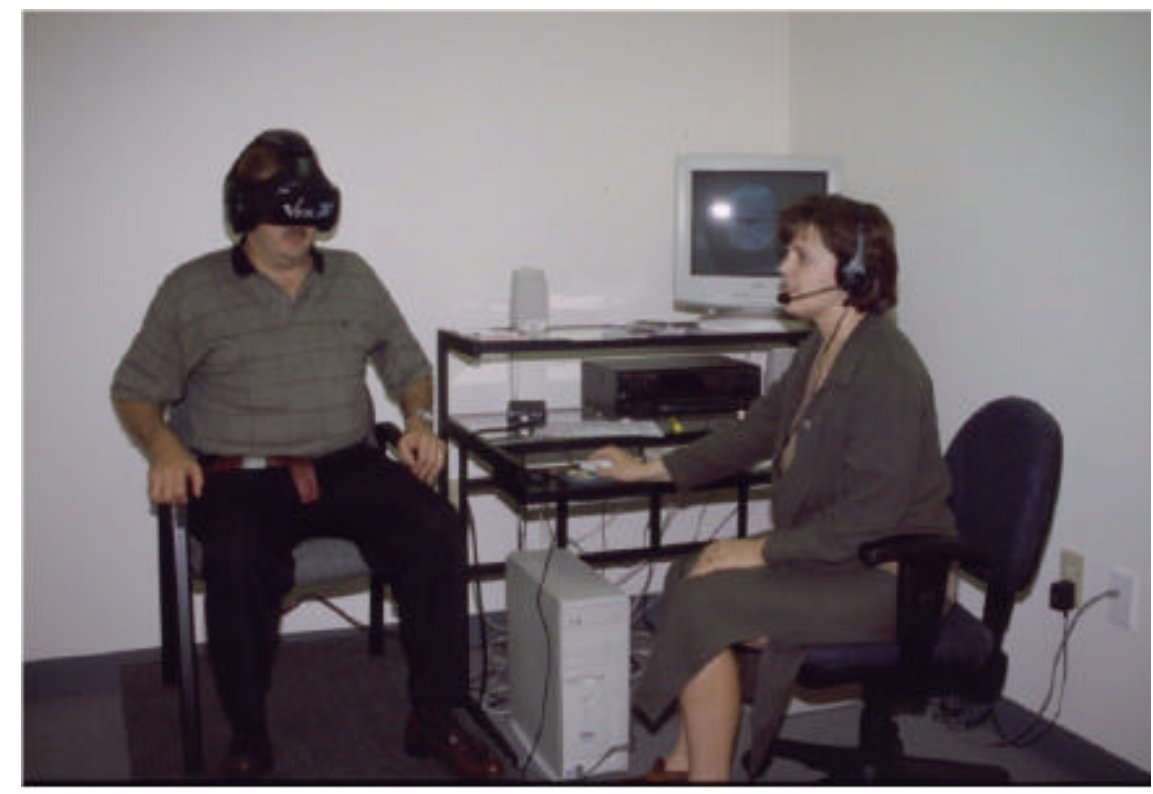

b)

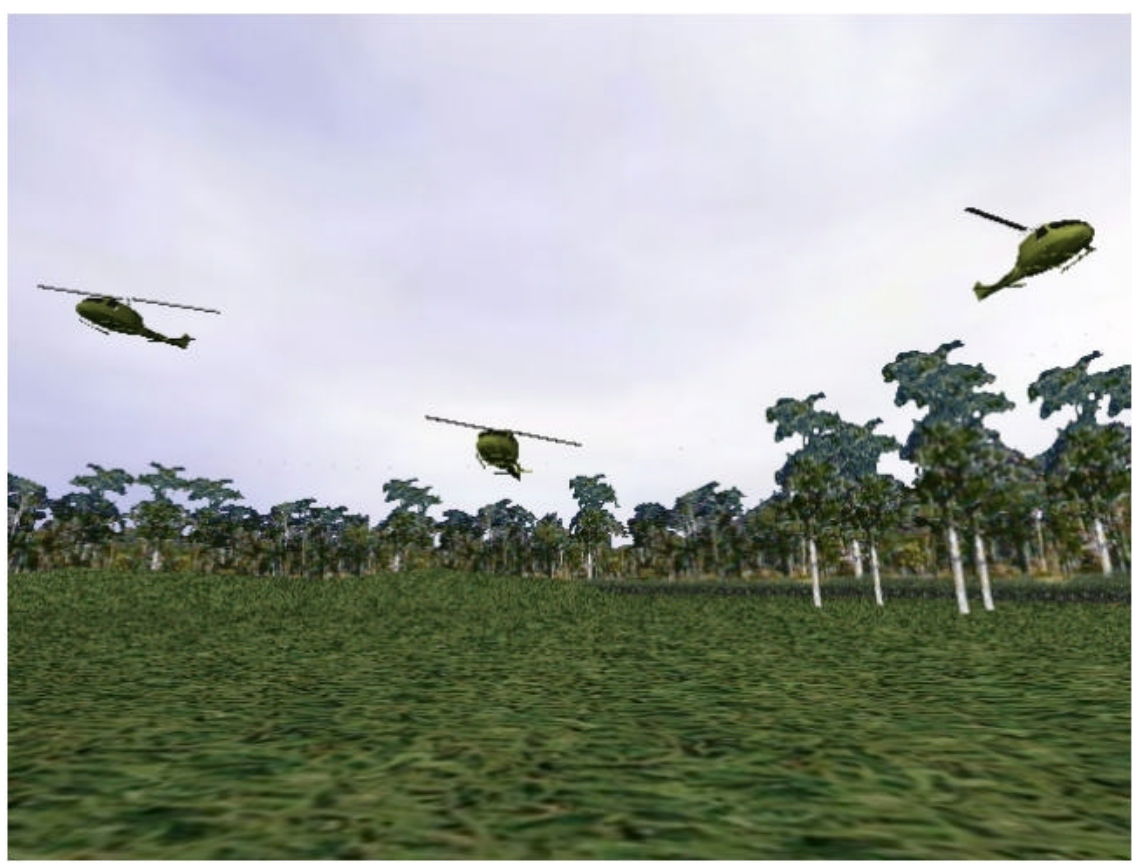

Fig. 4. Virtual Rehabilitation of patients with cognitive defficits: (a) office visit; (b) virtual scene used in desensitizing Vietnam vererans [7]. () Virtually Better 2000. Reprinted by permission.

encouraging, especially with respect to post-stroke chronic patients. VR by itself has been shown to improve them years after stroke, long after any classical therapy stopped $[8,3]$.

The therapist's attitude towards the technology is another challenge. Certain unwise (and short-sighted) technologists have proclaimed that Virtual Rehabilitation will replace the therapists altogether with computers.
This misconception needs to be quickly rectified, lest our field is in danger. In truth Virtual Rehabilitation is a "force amplifier" for the therapist, allowing him to do more, and with more patients. The intricacies of computers, VR interfaces and networks is something therapists are not exposed to as part of their academic training, and resistance to such technology is widespread. This unfortunate technology gap is 
counterbalanced by a positive, accepting attitude from the patients and their caregivers. Faced with no alternative, the patients and their families clearly embrace Virtual Rehabilitation [4].

The VR interfaces currently in use are another challenge. They were not designed as medical equipment, which means they have difficulty being sterilized for repeated use by different patients. Furthermore, standard VR equipment cannot accommodate "special needs." One example is the lack of child-size equipment, which hampers VR-based assessment of children with attention deficit/hyperactivity syndrome [12]. Even adult-size equipment has shortcomings, for example patients that underwent hand surgery, or suffered a stroke, have difficulty donning sensing gloves, designed for normal anatomy. The commonly-recognized limited range of trackers, and the weight of haptic feedback equipment pose usability constraints, which reduce the naturalness of interaction, so important for cognitive patients.

Equipment cost has dropped significantly in recent years compared to the hundred of thousand of dollars that VR systems used to cost less than five years ago. Nevertheless, current prices are still prohibitive for health clinics, or for schools, and these institutions will be hesitant to invest in the absence of subsidies, or a vocal patient advocacy. Dhurjarty [5] suggests that game interfaces, such as the $\mathrm{x}$-cube may be the answer. Of course, this assumes a more open programming environment than presently exists in the video-game industry.

Telerehabilitation has additional challenges relating to inadequate (or absent) communication infrastructure. The use of telephone lines does limit videoconferencing between therapist and the remote patient. Fortunately, certain forms of Telerehabilitation do not require constant supervision. Nevertheless, videoconferencing may be requested by patients when they have difficulty. If networks are used, then network traffic becomes the bottleneck, a problem that willeventually be solved by broadband, and widespread connections, some wireless.

Another important aspect of Telerehabilitation is patient safety. While patients exercise in VR, they are in danger of re-injury due either to large forces applied by robots or other feedback interfaces, due to cables and tethers, or due to over-exercising. Thus software "watch dog" programs need to be integrated at the patient's home to make sure he is not exercising at a higher level then prescribed, or for a longer duration than necessary.

Since Telerehabilitation is a newer form of therapy, it is unclear at this time how psychological factors will influence recovery. Certain patients may exercise less without direct therapist intervention, since they feel they get less attention than they deserve. Others will prefer less human contact, thus large-scale studies are needed to elucidate questions like: "Is Telerehabilitation as efficacious as Virtual
Rehabilitation done at a clinic?" "Is it as good as classical rehabilitation, all else being equal?"

\section{Summary}

This article reviewed the benefits brought by Virtual Rehabilitation use in various forms of therapy. A number of challenges exist at this time, and need to be addressed if Virtual Rehabilitation is to gain wide acceptance. Table 1 is a summary of our discussion. It is the belief of this author, based on years of related research, and on the review of pertinent literature, that Virtual Rehabilitation will overcome the current challenges. Of course, you the researcherwill play a key role in the work that lies ahead. We wish you success!

\section{Acknowledgements}

Research support for studies done by the author came from the National Science Foundation (BES-0201687), and from the New Jersey Commission on Science and Technology (R\&D Excellence Grant).

Table 1. Virtual Rehabilitation benefits/challenges comparison @ Rutgers University 2002

\begin{tabular}{|c|c|c|}
\hline Virtual Rehabilitation & Benefits of Virtual Rehab & Challenges posed by Virtual Rehab \\
\hline Neuro-muscular & $\begin{array}{l}\text { Engaging/motivating } \\
\text { Economy of scale } \\
\text { Online data gathering } \\
\text { Fine time resolution } \\
\text { Impairment/Function } \\
\text { Malingering detection }\end{array}$ & $\begin{array}{l}\text { Expensive equipment } \\
\text { Clinic and clinical acceptance } \\
\text { Technical expertise }\end{array}$ \\
\hline Post-stroke & $\begin{array}{l}\text { Engaging/motivating } \\
\text { Economy of scale } \\
\text { Repetitive/intensive } \\
\text { Adaptable to patient condition } \\
\text { Usable in chronic phase } \\
\text { Impairment/Function } \\
\text { Activities of daily living }\end{array}$ & $\begin{array}{l}\text { Abnormal limb configuration } \\
\text { Applicable to upper functional } \\
\text { population } \\
\text { Technical expertise } \\
\text { Clinical acceptance } \\
\text { Cognitive load }\end{array}$ \\
\hline Cognitive & $\begin{array}{l}\text { Economy of scale } \\
\text { Engaging/motivating } \\
\text { Increased privacy } \\
\text { Reduced costs } \\
\text { Increased safety } \\
\text { More realistic assessment }\end{array}$ & $\begin{array}{l}\text { Lack of natural interfaces } \\
\text { Lack of child-size equipment } \\
\text { Large equipment cost (for schools) } \\
\text { Technical expertise }\end{array}$ \\
\hline Tele-rehabilitation & $\begin{array}{l}\text { Availability of therapists } \\
\text { Rehabilitation at home } \\
\text { Reduced therapist cost } \\
\text { Improved compliance } \\
\text { Reduced isolation } \\
\text { Remote database access }\end{array}$ & $\begin{array}{l}\text { Equipment cost } \\
\text { Network bandwidth } \\
\text { Technical expertise } \\
\text { Safety at home } \\
\text { Sterilization for redeployment } \\
\text { Efficacy studies } \\
\text { Psychological factors }\end{array}$ \\
\hline
\end{tabular}




\section{References}

1. American Association of Orthopedic Surgeons. Broken Ankl; 2002. Also at orthoinfo.aaos.org.

2. American Stroke Association. Impact of Stroke; 2002. Also at www.strokeassociation.org.

3. Boian R, Sharma A, Han C, Burdea G, Merians A, Adamovich S, et al. Virtual Reality-Based Post-Stroke Hand Rehabilitation. Proceedings of Medicine Meets Virtual Reality 2002, Newport Beach CA, January 23-262002. IOS Press; 2002. p. 64-70.

4. Buckley K, Prandoni C, Tran B. Nursing Management and the Acceptance/Use of Telehealth Technologies by Caregivers of Stroke Patients in the Home Setting. Proceedings of State of the Science Conference on Telerehabilitation and Applications of Virtual Reality, Washington DC; October 2001. p. 35-8.

5. Dhurjaty S. Challenges of Tele- rehabilitation in the Home Environment. Proceedings of State of the Science Conference on Telerehabilitation and Applications of Virtual Reality, Washington DC; October 2001.p. 89-93.

6. Emory Health Sciences. Virtual Reality Therapy Proven Effective to Combat Fear of Flying. Press Release, December 18 2000. www.emory.edu.

7. Hodges L, Anderson P, Burdea G, Hoffman H, Rothbaum B. Treating Psychological and Physical Disorders with VR. IEEE Computer Graphics and Applications, November/December 2001: 25-33.

8. Holden M, Todorov E. Use of Virtual Environments in MotorLearning and Rehabilitation. In: Stanney K, editor. The Handbook of Virtual Environments Technology (HVET), Lawrence Erlbaum Associates, Inc.; 2002. p. 999-1026.

9. National Rural Health Association. Legislative and Regulatory Agenda. NRHA e-News, Washington DC 1999; 2(3). www.nrharural.org.
10. North M, North S, Coble J. Virtual Reality Therapy: An Effective Treatment for Psychological Disorders. In Stanney K, editor. The Handbook of Virtual Environments Technology (HVET). Lawrence Erlbaum Associates, Inc.; 2002.p. 1065-78.

11. Popescu V, Burdea G, Bouzit M, Girone M, Hentz V. Orthopedic Telerehabilitation with Virtual Force Feedback. IEEE Trans Inf Technol Biomed March 2000; 4(1):45-51.

12. Rizzo A, Schultheis M,Mateer C. Analysis of Assets for Virtual Reality Applications in Neuropsychology. Neuropsychological Rehabilitation (in press).

Address of the author:

Grigore Burdea, Ph.D.

CAIP Center, Rutgers University

96 Frelinghuysen Rd.

Piscataway NJ, 08854 USA

E-mail: burdea@caip.rutgers.edu 